\title{
HERMENÉUTICA DEL OLVIDO
}

En torno a un poema manuscrito atribuido póstumamente a Borges

Francisco Naishtat 


\section{Francisco Naishtat}

Consejo Nacional de Investigaciones Científicas y Técnicas

Universidad Nacional de Buenos Aires

\section{Hermenéutica del olvido: en torno a un poema manuscrito atribuido póstumamente a Borges}

DOI: $10.36446 /$ be.2021.55.257

\section{Resumen}

Este artículo parte de un poema manuscrito atribuido póstumamente a Jorge Luis Borges, titulado “Aquí. Hoy" y editado por el crítico colombiano Abad Faciolince. Sin entrar en el problema de la autenticidad de este poema, lo que interesa es su argumento metafísico en conexión con lo que se caracteriza aquí como una "hermenéutica del olvido", convocando a Paul Ricœur, Friedrich Nietzsche, Jean-Paul Sartre, Martin Heidegger, Walter Benjamin y otros filósofos que inauguraron una reflexión sobre el olvido con raíces fenomenológicas, ontológicas, antropológico-existenciales e históricas. En particular, el autor polariza un pensamiento (in)existencial del olvido a través de la noción de Nachleben con la que Benjamin, en su obra temprana, aborda la temática de la ruina y la espectralidad.

\section{Palabras clave}

Poesía; Hermeneusis; Memoria; Historia; Postvida

\section{Hermeneutics of Oblivion: Around an Unpublished Poem Posthu-} mously Attributed to Borges

\section{Abstract}

This paper is based on a handwritten poem posthumously attributed to Jorge Luis Borges, entitled "Here. Today", and edited by the Colombian critic Abad Faciolince. Without going into the problem of the authenticity of this poem, what interests is its metaphysical argument, in its connection with what is characterized here as an "hermeneutics of forgetting", summoning Friedrich Nietzsche, Jean-Paul Sartre, Martin Heidegger, Walter Benjamin, and other philosophers who have inaugurated a reflection on the forgetting with phenomenological, ontological, anthropological-existential, and historical roots. In particular, the author polarizes an (in)existential thought of forgetting through the notion of Nachleben with which Benjamin, in his early work, approaches the theme of the ruin and the spectrality.

\section{Keywords}

Poetry; Hermeneusis; Memory; History; After-Life

Recibido: 03/11/20. Aprobado: 01/02/21.
Ya somos el olvido que seremos

El olvido aparece generalmente, en el sentido común y en la literatura, defectivamente, como un defecto de la memoria y de rango conceptual subordinado: existe, por ejemplo, un deber de memoria, pero no un deber de olvido. Sin embargo, algunos hitos conceptuales atenúan esta impresión: en la segunda de las Consideraciones intempestivas (1874) de Friedrich Nietzsche, "De la utilidad y perjuicio de la historia para la vida", leemos: "Es absolutamente imposible vivir sin olvidar [...] se trata de saber olvidar adrede [...]. El sentido no histórico y el histórico son igualmente necesarios para la salud de un individuo, de una acción, de un pueblo y de una cultura (KSA 1: 251252). Dentro de la tradición hermenéutica contemporánea, Paul Ricoeur ha dedicado al tema la última sección de La memoria, la historia, el olvido (2000: 536- 589). Las actas del Coloquio de Royaumont, celabrado en 1993, contienen intervenciones sobre los "usos del olvido” de Yosef Yerushalmi, Nicole Loraux, Hans Mommsen, JeanClaude Milner y Gianni Vattimo. No menos valioso son los libros de Jean-Louis Chrétien, L'inoubliable et l'inesperé (1991) y, más recientemente, In Praise of Forgetting (2016) de David Rieff.

Nuestro punto de partida en esta meditación es un poema manuscrito atribuido póstumamente a Jorge Luis Borges y titulado “Aquí. Hoy", que diera a conocer, junto con otros cuatro sonetos inéditos, el crítico literario colombiano Abad Faciolince en 2009. Sin entrar 
aquí en la polémica acerca de la autenticidad o el carácter apócrifo de este material, nos interesa la meditación del poema desde una perspectiva (in)existencial (Naishtat 2016) en conexión con lo que llamaremos "una hermenéutica del olvido", asumiendo una intertextualidad marcada por fragmentos de Nietzsche, Ricoeur, Jean-Paul Sartre, Vladimir Jankélévitch, Martin Heidegger y Walter Benjamin.

Permítasenos transcribir aquí el soneto de Borges:

Ya somos el olvido que seremos.

El polvo elemental que nos ignora

y que fue el rojo Adán y que es ahora

todos los hombres, y que no veremos.

Ya somos en la tumba las dos fechas del principio y el término. La caja, la obscena corrupción y la mortaja, los triunfos de la muerte, y las endechas.

No soy el insensato que se aferra al mágico sonido de su nombre. Pienso con esperanza en aquel hombre que no sabrá que fui sobre la tierra. Bajo el indiferente azul del cielo, esta meditación es un consuelo.

(Faciolince 2009)

El poema parte del leitmotiv "Ya somos el olvido que seremos". El autor cruza, escatológicamente, la línea del presente con la anticipación y proyección del futuro, pero de un futuro que, kairológicamente (Agamben 2000), está ya siendo, que está ya negándonos, esto es, olvidándonos, abriendo, en el ahora-tiempo del kairós, mediante la forma verbal "ya somos el olvido que seremos", el horizonte de nuestra nada, en futuro-presente, dominado por el polo destinal de la muerte, no solo biológica, sino simbólica, esto es, del nombre y no meramente del cuerpo propio (Lacan [1963] 2002a). En un poema titulado "El suicida", que integra La rosa profunda (1975), Borges apunta a nuestra muerte simbólica, no solo como un suceso terminal en la línea del tiempo vital, sino en la tonalidad del final mismo del todo, es decir, el "final de la misma manifestación" (Lipsitz 2017), de la experiencia, y por ende del nombre propio, lo que, para él, al igual que para el marqués de Sade (Lacan [1963] 2002a) y, de modo solapadamente inexistencial, es un consuelo:

No quedará en la noche una estrella.

No quedará la noche.

Moriré y conmigo la suma

del intolerable universo.

Borraré las pirámides, las medallas,

los continentes y las caras.

Borraré la acumulación del pasado.

Haré polvo la historia, polvo el polvo.

Estoy mirando el último poniente.

Oigo el último pájaro.

Lego la nada a nadie.

(Borges 1998: 434)

Con excepción de los últimos tres versos en presente del indicativo, el tiempo verbal aquí es el futuro del indicativo. En efecto, Borges no despliega, como en el soneto atribuido, el tiempo verbal del futuropresente en tonalidad kairológica de lo que está ya teniendo lugar. Sin embargo, este poema expresa, del modo más acuciante, que con nuestra muerte no solo se cierra la posibilidad de nuestro futuro, sino que incluso el mismo pasado se borra. Por ende, si con mi muerte todo mi pasado se borra, mi ahora-tiempo kairológico, que no es sino

\footnotetext{
${ }^{1}$ Agradezco al poeta y ensayista argentino Miguel Espejo el haberme indicado la
} relevancia de este poema en consonancia con esta meditación. 
pasado de mi muerte futura, habrá sido borrado, una forma que refuta el ego cogito propio del presente de la conciencia, oponiendo al "pienso, existo" de Descartes en indicativo presente, un "no habré sido nunca" en futuro anterior (Lipsitz 2017), que no es sino la otra cara del primer verso de poema editado por Faciolince: "ya somos el olvido que seremos".

Hay, sin embargo, una creencia arraigada en nuestra intuición ordinaria del tiempo acerca de la irreversibilidad absoluta del pasado, según la cual, mientras los sucesos del futuro son contingentes, ${ }^{2}$ los acontecimientos del pasado revisten, una vez que han tenido lugar, un carácter absoluto e inamovible. En este sentido, Ricoeur reproduce un fragmento de Vladimir Jankélévitch en el epígrafe de La memoria, la historia, el olvido, que lo expresa sin reservas: "El que fue ya no puede no haber sido: en adelante, este hecho misterioso y profundamente oscuro de haber sido es su viático para siempre" (2000: X; 2008: 9).

Este carácter absoluto de lo hecho y lo sido triunfaría inclusive contra la más absoluta nada, cuyo poder no alcanzaría para borrar el más ínfimo acto ni la más ínfima criatura, con tal de que estos hayan tenido lugar alguna vez, aunque apenas fuera por el lapso de un instante. Y esto haría algo absoluto de nuestros actos, por contingentes que fueran. ¿No es, en este sentido, que se expresa Frantz von Gerlach, el héroe de la obra teatral de Jean-Paul Sartre Los secuestrados de Altona, cuando alega desde una grabación en off:

Este siglo es una mujer, da a luz. ¿Vais a condenar a vuestra madre? ¿Eh? ¡Respondedme! (una pausa). El siglo treinta no

\footnotetext{
${ }^{2}$ Recuérdese en este mismo sentido el alegato de Aristóteles de los futuros contingentes a través de su célebre ejemplo: "Habrá batalla naval mañana" (De Int., 19a30 ss.).
}

responde ya. Puede que no llegue a haber más siglos después del nuestro. Puede que una bomba haya apagado un día todas las luces. Entonces todo estará muerto: los ojos, los jueces, el tiempo. Todo... Noche. ¡Oh tribunal de la noche, tú que fuiste, que serás, que eres, mira que yo también he sido! ¿Qué yo también he sido! Yo, Frantz von Gerlach, aquí, en esta habitación, me he puesto el siglo encima de mis hombros y he dicho: Yo responderé por él. En este día y para siempre. ¡Eh!, ¿qué? (Sartre 1960: 375; 1970: 883)

Sin embargo, no son pocos los alegatos filosóficos que indican una fragilidad ontológica no solo del futuro, sino asimismo del pasado. En primer lugar, esta fragilidad puede respaldarse en la vanidad e intrascendencia del hombre, cuya insignificancia en la escala del cosmos sería de tal magnitud que amputaría de raíz cualquier pretensión de verdad absoluta, incluida aquella que apunta al pasado, de suerte que de su pequeñez acuciante podría inferirse que "con él no habrá pasado nada".

El joven Nietzsche, en "Sobre la verdad y la mentira en sentido extramoral” (1873), declina la condición cosmológica de la existencia humana en este preciso sentido, bajo el tiempo del futuro anterior:

Hubo eternidades en las que [el intelecto humano] no existía; cuando de nuevo se acabe todo para él no habrá sucedido nada, puesto que para ese intelecto no hay ninguna misión ulterior que conduzca más allá de la vida humana. (Nietzsche (2001: 17)

Esta forma verbal referida al desvanecimiento de la huella reaparece como leitmotiv en la parte final del célebre poema de Mallarmé "Un golpe de dados": 
NADA

de la memorable crisis

o se produjo

el acontecimiento realizado en vista de todo resultado nulo humano

HABRÁ TENIDO LUGAR

(Mallarmé 1985: 444-445; 2008: 45-46) ${ }^{3}$

Esta primacía del destino respecto del presente aparece en el primer Heidegger bajo la figura del precursar o adelantarse [Vorlaufen] q la muerte como característica del Dasein (Heidegger 2006a: 270-287), siendo su reflexión una de las raras donde esta polaridad adquiere una tonalidad existencial central en detrimento de la evidencia apodíctica que la fenomenología de tradición cartesiana atribuye al ego cogito. Sin embargo, nos interesa polarizar aquí este pensamiento radical de la muerte con la noción de Nachleben ("pervivencia", "Afterlife", "survivance" y, literalmente, "post-vida") introducida por Walter Benjamin, en su célebre ensayo "La tarea del traductor" (1923), para abordar la temática de la ruina y la espectralidad (Benjamin 2010: 9-22).

\section{II}

Ya somos en la tumba las dos fechas del principio y el término. La caja,

la obscena corrupción y la mortaja, los triunfos de la muerte, y las endechas.

En "EL concepto de tiempo en la ciencia histórica" (1915), su conferencia en la Universidad de Friburgo para obtener la venia legendi, el joven Heidegger despejó la noción de tiempo implícita en la

\footnotetext{
${ }^{3}$ La distribución de mayúsculas y minúsculas como la disposición espacial de las
} palabras en el poema siguen la grafía original francesa dispuesta por el poeta. persecución de metas y, en relación con esta noción de tiempo, consideró el concepto de pasado histórico, que está presupuesto en la historiografía. Para Heidegger, aquí el objeto histórico "ya no existe”:

El objeto histórico, en cuanto histórico, es siempre pasado; en sentido estricto ya no existe más (Heidegger 1978: 427; 2009: 31)

Heidegger extrae de esta premisa dos conclusiones fundamentales: (i) el pasado solo es para un presente; (ii) ese pasado no es para nosotros lo que fue "en sí mismo" (Heidegger 1978: 427); (iii) hay, en consecuencia, una lejanía temporal [Zeitferne], inclusive un abismo entre el historiador y el pasado, que solo se puede recubrir merced a los valores del presente y a una resolución de la existencia mediada por la inherencia de valor [Wertbeziehung] en el presente, al modo en el que Heinrich Rickert planteaba desde 1902 la selección y conocimiento del objeto historiográfico (ibid., 433).

Por ende, Heidegger da de lleno con un abismo temporal entre el pasado y el presente; en otras palabras, desde 1915 da con un problema ontológico y existencial en relación con el pasado, lo que conduce a la dificultad del rellenado de esta brecha. La respuesta en su conferencia de Friburgo es que es merced al presente que se articulan los dos tiempos, es decir, merced a los valores que permiten la selección historiográfica. En 1924, en su conferencia El concepto de tiempo, impartida en Marburgo, Heidegger, anticipando la segunda sección de Ser y tiempo, afirma que "el pasado experimentado como historicidad propia, es todo menos lo que se fue. Más bien, es algo a lo que puedo volver una y otra vez" (GA 64: 123; Heidegger 2006b: 56-57). 
Entretanto, Heidegger ha opuesto la mera historia [Geschichte] como dimensión óntica de la "secuencia de ahoras" a la historicidad [Geschchitlichkeit], como dimensión ontológica enraizada en la "temporeidad". La historicidad es el modo de ser del Dasein, en cuanto que es su historia y no meramente algo en la historia; el Dasein es el tiempo, y no un ente en el tiempo (GA 64: 58-59). A esto corresponde la figura del "estiramiento del Dasein", que Heidegger despliega en Ser y tiempo, consagrando su quinto capítulo de la segunda sección, titulado precisamente "Temporeidad e historicidad", a explicitar la idea de "conexión de la vida" ( $S Z$ \$72: 373 y 375). Heidegger toma esta figura en préstamo de Wilhelm Dilthey para situar al Dasein como un "entre" de su nacimiento a su muerte (ibid., 374), en cuanto que el Dasein está siendo su pasado y que este mantenimiento suyo del pasado en el presente, expresado mediante la noción de ecstasis temporal ( $S Z \$ 65: 329 ; \$ 67: 338$ ), hunde a la vez su posibilidad en la misma proyección del futuro y de su "ser-para-la-muerte", de modo que el Dasein mantiene el pasado anudado a su presente porque precisamente proyecta su horizonte de posibilidad como futuro, y en ello su muerte misma como la marca de su finitud y el fin de todas sus posibilidades. Esta perspectiva, como decimos, se va a desplegar en Ser y tiempo en los seis capítulos de su segunda sección.

Ahora bien, si según Heidegger precursamos, mientras existimos, nuestro haber sido [Vorbei], es decir, nuestra muerte (GA 64: 116; $S Z$ $\S 53: 260-267)$, y si nuestro haber sido no es para el Dasein un dato óntico, sino que es cada vez, ontológicamente, nuestro, ¿qué es entonces de nuestro haber sido cuando ya no somos? Si el haber sido es siempre el nuestro, a través del mantenimiento que realiza el Dasein de su tiempo en las ecstasis temporales, cuando ya no existimos, lo Vorbei, lo haber sido de nosotros mismos, ¿no deviene en algo meramente "óntico" e "impropio"? Llevando al límite esta posición, ¿no es acaso que, con nuestra muerte, seríamos nuestro no haber sido, e incluso nuestro no haber sido nunca? ${ }^{4}$ Tal es según entendemos el reverso inconfesado de la posición de Heidegger, como el negativo de la Zeitlichkeit heideggeriana, la cual constituye, si se nos permite la expresión, una aporía inexistencial, es decir, el negativo inexistencial de la existencialidad.

La temática de la muerte, en efecto, yace en el centro de la temporalización trágica heideggeriana y, por ende, de su historicidad. El "serpara-la- muerte" es lo propio de la Geworfenheit, de nuestro estar arrojado y de nuestra finitud como facticidad. Y si la caída, es rehuir la proyección al futuro, caer en el presente y ver el pasado como "secuencia de ahoras", la autenticidad es, en cambio, hacerse cargo del "ser-para-la-muerte" o el precursar la muerte. Las elecciones auténticas del Dasein proyectadas en un destino singular [Schicksal] se entretejen así para formar el destino [Geschick] de un pueblo. El entretejido coincidente de destinos encuentra su locus en la generación. ¿Pero qué es esta "autenticidad comunal”?

En Dilthey, la Generation era un concepto que permitía medir el tiempo en la escala histórica; en Heidegger se la pretende ver ontológicamente. ¿Y qué es la autenticidad en relación con un pueblo? Los críticos coinciden en que hay ahí una vaguedad y una incompletud de la noción de generación en Heidegger (Jeffrey Barash 2017: 193199). No hay, desde esta tematización del pasado propio, ninguna diferencia cualitativa entre la dimensión del sí mismo individual y

${ }^{4}$ Esta reflexión sobre la muerte en Heidegger debe mucho a la discusión mantenida con Mario Lipsitz en la última década (en particular véase Lipsitz 2017), con quien hemos realizado una jornada en la que se abordó esta problemática, en la Universidad Nacional de General Sarmiento, el 25 de noviembre de 2016, titulada "Inexistencialismo y ontología. Mundanidad, Mortalidad, Finitud. Conversaciones filosóficas": http://www.ungs.edu.ar/ms_ici/index.php/inexistencialismo-y-ontologia-mundanidadmortalidad-finitud 
del sí mismo histórico. ¿Tiene sentido plantearse, como hace Heidegger, una autenticidad en el plano de la comunidad histórica en relación siempre con este "ser-para-la-muerte"? Si cada individuo reconoce auténticamente en su muerte personalísima su posibilidad más próxima, ¿es acaso la figura de la muerte la que permite pensar "lo propio" en relación, no ya con el individuo, sino con la comunidad? ¿No hay acaso, al pasar del individuo a la comunidad, una segunda figura que irrumpe con cierta fuerza ontológica, a saber, la figura de la pervivencia del pasado [Nachleben], que parece desplazar el polo de la muerte individual en provecho de una transmisión?

El plano de lo colectivo nos parece, en efecto, generar una asimetría ontológica respecto de la dimensión existencial de la muerte, no en términos de una eternidad ni de una esencialización histórica, que dejaría como a salvo a la historia (o la tradición) en una redimida posteridad ultraterrena, sino simplemente como la idea de una transmisión frágil, sin garantía, y en peligro, enteramente vulnerable, pero no menos perviviente.

\section{III}

Pienso con esperanza en aquel hombre que no sabrá que fui sobre la tierra.

Bajo el indiferente azul del cielo, esta meditación es un consuelo.

Pero es aquí donde la perspectiva anti-egocéntrica de Benjamin, inscripta en su rechazo a la tradición intencionalista de la fenomenología, ${ }^{5}$ se cifra en no reducir ni derivar de nuestra propia intencionali-

${ }^{5}$ Actitud anti-intencionalista afirmada de modo contundente en su célebre sentencia del "Prólogo epistemo-crítico" de su libro sobre el Trauerspiel: "La verdad es la muerte de la intención" (GS 1/1: 216; Benjamin 2006: 231). dad el tiempo histórico. Ya en su Metafísica de la juventud (19131914) Benjamin hablaba del "tiempo de las cosas" (GS 2/1: 99). Pero este planteo no tiene nada de mecanicista, ya que, lejos de desembocar en el paradigma de lo cuantificable y de la reversibilidad que gobierna la temporalidad mecánica, "el tiempo de las cosas" es comprendido en relación con el ritmo del "decaer", de la "caducidad" y de la "ruina", que es propio de lo que Benjamin interpreta, en el libro sobre el Trauerspiel, como "historia natural". Esta idea se expresa a la vez como tiempo de la naturaleza y como facies hippocratica de la historia humana, es decir, como caducidad y arruinamiento, capturados en la "visión alegórica" como ruina o "paisaje primordial petrificado" (GS 1/1:343).

Benjamin resume esta carga temporal de las cosas señalando que "[l]as alegorías son en el reino de los pensamientos lo que las ruinas en el reino de las cosas" (GS 1/1: 354; Benjamin 2006: 396). Si las ruinas se comportan entre las cosas como las alegorías entre los pensamientos, esto quiere decir que las ruinas son portadoras no solo de tiempo, sino también de ausencia, y que esta ausencia, condensada en la función alegórica de la ruina, interrumpe el decurso continuo y homogéneo de nuestro presente, en cuanto tránsito del pasado al futuro, para detener y saturar el tiempo como condensación cargada de tensión. Esta idea de un tiempo de las cosas y en las cosas es una perspectiva mantenida por Benjamin a lo largo de su obra: en su concepción, el pasado no es una cuestión de "miidad" [Jemeinigkeit] sino una cuestión de "transmisión” [Überlieferung].

Hay un relato póstumo de Franz Kafka titulado "Un mensaje imperial", que Benjamin recoge en sus emisiones radiales sobre el escritor checo de 1931 (véase Kafka 2003: 187-188; GS 2/1: 676-683 y Benjamin 2014: 25-64). En él se cuenta la historia de un mensajero que, en el momento de la agonía del emperador, es convocado por este a su 
lecho de enfermo. Rodeando al emperador están los notables de la corte que le abren paso, y el emperador dice en secreto y al oído del mensajero unas palabras que solo el mensajero escucha, encomendándole que transmita a un destinatario, al otro extremo del imperio, esas mismas palabras. $\mathrm{Y}$ al decirlo, el emperador muere, ante la vista de una infinita masa de público congregada en los jardines. Solo para salir de la capital del imperio, el infortunado mensajero debe atravesar innúmeros palacios, antes de traspasar incluso la gran ciudad, en una dificultad que se va multiplicando a medida que el mensajero intenta abrirse paso, de modo que rápidamente llega a la conclusión de que jamás va a poder, en el lapso de su breve vida, hacer llegar el mensaje al destinatario.

El relato de Kafka concluye con la imagen irónica de que el destinatario quizá estaba en esos momentos soñando el mensaje del emperador. Podríamos, por de pronto, pensar a la luz de este relato el problema, muchas veces descuidado por la tradición hermenéutica, de la mera transmisión material del mensaje. Se trata de comprender la Erfahrung, la "experiencia” en sentido enfático, no ya como un hecho o vivencia de conciencia [Erlebnis], sino como un anudamiento descentrado de experiencias intersubjetivas, pervivientes, heterogéneas entre sí y, sin embargo, articuladas o diseminadas en un reticulado de interacciones en el tiempo, que no están tanto en relación con la vivencia de un mismo yo, cuanto en relación a la traducción de diferentes lenguajes, o a la pervivencia de diferentes estratos, de diferentes desechos, ruinas e imágenes del pasado, ciertamente cargados de tiempo. Nuestra experiencia del pasado se ordenaría, entonces, en los planos de la pervivencia [Nachleben], del salvataje [Rettung] y de la redención [Erlösung], privando al polo de la muerte del carácter que asumía en Heidegger en cuanto unidad del Dasein y fuente primordial de su autenticidad.
Pero, para abordar este desplazamiento, es necesario transitar del plano hermenéutico-fenomenológico de la intencionalidad de la conciencia al plano antropológico, etnográfico y arqueológico del anacronismo, quizá acompañados por otros pensadores contemporáneos de Benjamin, como Aby Warburg o Ernst Bloch y por sus seguidores de las generaciones siguientes, como Georges Didi-Huberman, en los que esta dimensión de lo perviviente es decisiva en las figuras de lo anacrónico, de la Nachleben y no menos de "la no simultaneidad de lo simultáneo" [Ungleichzeitigkeit des Gleichzeitigen]. En otro relato, bastante más breve que el anterior, titulado "El pueblo más cercano", Kafka escribió:

Mi abuelo solía decir: - la vida es asombrosamente corta. Ahora, en el recuerdo, se me aparece tan de un solo golpe que apenas puedo comprender cómo, por ejemplo, un joven pueda decidirse a cabalgar hasta el pueblo más próximo sin temer que -posibles accidentes aparte- ya el tiempo mismo de la vida que transcurre normal, feliz, pueda no alcanzar ni por mucho para semejante cabalgata. (Kafka 2003: 187)

Benjamin se refiere a este relato en los materiales preparatorios a su ensayo "Franz Kafka: En el décimo aniversario de su muerte" (1934). El fragmento importa porque, aunque años antes, Benjamin había declarado que se rehusaba a interpretar "Un mensaje imperial", aquí apunta lo siguiente:

"El pueblo más cercano". Brecht: esta historia es la contraparte de la de Aquiles y la tortuga. Alguien cualquiera no llegará jamás al pueblo más cercano si va componiendo la cabalgata a partir de las más pequeñas partes, sin contar los contratiempos. Entonces la vida es demasiado corta para esta cabalgata. Pero el error está aquí en ese "alguien" [ "einer"]. Pues, así como la cabalgata se descompone en partes, así también el jinete. Y así como la unidad de la vida [Einheit des Lebens] 
está perdida, también lo está su brevedad. Que sea tan breve como quiera, esto nada cambia, pues llegará al pueblo otro distinto del que se marcha a caballo. (GS 2/3: 1253; Benjamin 2014: 203)

Con esto retornamos a los últimos versos del soneto atribuido a Borges que dio origen a este escrito: el autor, luego de señalar que no pretende aferrarse a su nombre, sorprende con una meditación sobre la esperanza y el consuelo, que vienen de "pensar en aquel hombre que no sabrá que fui sobre la tierra". ¿No distiende y consuela esa mirada anónima de nosotros mismos, aflojando, por así decir, la tensión y la carga que pesan sobre nuestras espaldas junto a la culpa y la deuda de haber sido?

Distiende, desde luego, con relación a la culpa y la deuda sobre las que descansan, en ultima ratio, los parámetros teológicos del individualismo posesivo. Distiende y libera, no para la irresponsabilidad o la impunidad, sino para la meditación en torno a una experiencia de nosotros mismos y de los demás plasmada en un plano de inmanencia radical. Que llamemos existencial o inexistencial a la distensión que proviene de relativizar ontológicamente nuestra posición individual, es lo que menos cuenta de cara a recuperar la fuerza de una experiencia que deconstruye el credo egocéntrico desde su misma raíz metafísica.

\section{REFERENCIAS}

AA.VV. (1998), Usages de l'oubli: Contributions au colloque de Royaumont (París: Seuil) [ed. esp.: Usos del olvido. Comunicaciones al Coloquio de Royaumont, trad. de Pablo Betesh (Buenos Aires: Nueva Visión) 1989].

AGAMBEN, Giorgio (2000), Il tempo che resta. Un commento alla "Lettera ai romani" (Turín: Bollati Boringhieri).

ARISTÓteles (1980), Peri herméneias - De interpretatione, trad. de Alfonso García Suarez y Julian Velarde Lombraña (Valencia: Universidad de Valencia).

BARASH, Jeffrey Andrew (2017), Martin Heidegger y el problema del sentido histórico (Buenos Aires: Prometeo).

BENJAMIN, Walter (GS), Gesammelte Schriften, ed. de Rolf Tiedemann y Hermann Schweppenhäuser con la colab. de Theodor w. Adorno y Gershom Scholem, 7 ts. (Frankfurt am Main: Suhrkamp) 1974-1991.

(2006), Obras, Libro I, vol. 1, ed. de Rolf Tiedemann y Hermann Schweppenhäuser, ed. de Rolf Tiedemann y Hermann Schweppenhäuser, trad. de Alfredo Brotons Muñoz (Madrid: Abada).

(2010), Obras, Libro IV, vol. 1, trad. de Jorge Navarro Pérez (Madrid: Abada).

(2014), Sobre Kafka. Textos, discusiones, apuntes, ed. de Hermann Schweppenhäuser, trad., prólogo y notas de Mariana Dinópulos (Buenos Aires: Eterna Cadencia).

BORGES, Jorge Luis (1998), Obra poética 1923-1985 (Buenos Aires: Emecé Editores).

ChretiEN, Jean-Louis (1991), L'inoubliable et l'inespéré (París: Desclée de Brouwe).

FACIOlinCE, Abad (2009), "Un poema en el bolsillo". Disponible en: https://www.letraslibres.com/mexico-espana/un-poema-en-el-bolsillo.

HeIDEGGER, Martin (GA), Gesamtausgabe, 81 ts. (Fráncfort del Meno: Vittorio Klostermann), 1975ss. 
(SZ), Sein und Zeit, (Tubinga: Max Niemeyer) 1961.

(2006a), Ser y tiempo, trad. de Jorge E. Rivera (Madrid: Trotta).

(2006b), El concepto de tiempo, trad. de Jesús A. Escudero (Madrid: Trotta).

(2009), Tiempo e historia, ed. y trad. de Jesús Adrián Escudero (Madrid: Trotta).

KAFKA, Franz (2003), Relatos completos, trad. de Francisco Zanutigh Núñez (Buenos Aires: Losada).

LACAN, Jacques (2002b), Escritos, tomo 2, trad. de Tomás Segovia (Buenos Aires: Siglo XXI).

[1963] (2002a), “Kant con Sade”, en Lacan (2002b: 727-754).

LiPSITZ, Mario (2017), “Un día nunca habré sido. Una reflexión sobre la significación existencial (y existenciaria) de la muerte en torno a Heidegger y Michel Henry", Conferencia en la Academia de Ciencias de Buenos Aires.

MALlARME, Stéphane (1985), Euvres (París: Classiques Garnier).

_ (2008), Un golpe de dados, trad. de Agustín Oscar Larrauri, (Córdoba: Babel).

NAISHTAT, Francisco (2016), "Inexistencialismo y ontología: mundanidad, mortalidad y finitud”. Conversaciones filosóficas con Mario Lipsitz, Universidad Nacional de General Sarmiento.

NIETZSCHE, Friedrich (KSA), Sämtliche Werke. Kritische Studienausgabe, 15 ts., ed. de Giorgio Colli y Mazzino Montinari, Berlín: Walter de Gruyter.

__ [1873], "Sobre verdad y mentira en sentido extramoral”, trad. de Luis Manuel Valdés Villanueva, en Nietzsche y Vaihinger (2001: 15-37).

NIETZSCHE, Friedrich \& VAIHINGER, Hans (2001), Sobre verdad y mentira / La voluntad de ilusión en Nietzsche, trad. de Luis Valdés y Teresa Orduña (Madrid: Tecnos).

Ricoeur, Paul (2000), La Mémoire, l'Histoire, l'Oubli (Paris: Éditions du Seuil) [ed. esp.: La memoria, la historia, el olvido, trad. de Agustín Neira (Buenos Aires: Fondo de Cultura Económica) 2008].
RIEFF, David (2016), In Praise of Forgetting.:Historical Memory and Its Ironie (New Haven: Yale university Press) [ed. esp.: Elogio del olvido: las paradojas de la memoria histórica, trad. de Aurelio Major (Barcelona: Random House) 2017].

SARTRE, Jean-Paul (1960), Les séquestrés d'Altona (París: Gallimard). [Versión castellana: Los secuestrados de Altona, en Sartre 1970: 721-883]

(1970), Obras Completas, t. 1: Teatro, trad. de Miguel Angel Asturias, Aurora Bernardez et. al. (Madrid: Aguilar) 